
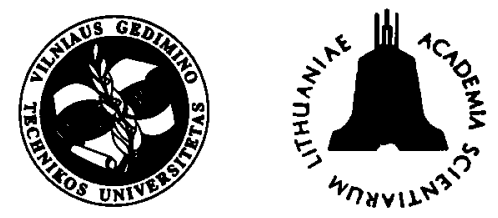

ISSN 1392-3730

JOURNAL OF CIVIL ENGINEERING AND MANAGEMENT

http:/www.vtu.lt/english/editions

2003, Vol IX, No 2, 122-13I

\title{
NUMERIC ANALYSIS OF LARGE PENETRATION OF THE CONE IN UNDRAINED SOIL USING FEM
}

\author{
Darius Markauskas', Rimantas Kačianauskas ${ }^{2}$ and Rolf Katzenbach ${ }^{3}$ \\ 1, ${ }^{2}$ Dept of Strength of Materials, Vilnius Gediminas Technical University, \\ Sauletekio al.11, LT-2040 Vilnius, Lithuania. 'E-mail:dm@fm.vtu.lt; ${ }^{2} E$-mail: rkac@fm.vtu.lt \\ ${ }^{3}$ Institute and Laboratory of Geotechnics, Darmstadt University of Technology, \\ Petersenstraße 13, D-64287 Darmstadt, Germany.E-mail: katzenbach@geotechnik.tu-darmstadt.de
}

Received 20 Dec 2002; accepted 20 Feb 2003

\begin{abstract}
Numeric analysis of the large penetration of the cone in undrained soil using finite element method (FEM) is presented. Until now the computation procedures has not been developed to such an extent, that they could provide numerical solution of large cone penetration problem. In this paper for solving of the large cone penetration problem an updated Lagrangian formulation and finite element method are used. To overcome large distortion of the finite element geometry during cone penetration leading to illconditioning equations a remeshing technique is developed. The proposed remeshing technique enables the simulation of the penetration process until steady cone penetration is reached. The analysis of the cone penetration in undrained soil is provided. The comparison of current numerical results and other authors' results are presented.
\end{abstract}

Keywords: cone penetration, FEM, large deformations, remeshing, patch recovery, undrained soil.

\section{Introduction}

Cone penetration test (CPT) is one of the most popular in-situ tests used to investigate the soil properties [1]. Assessment of cone testing results is usually based on the relationships between soil properties and soil resistance to cone penetration. Many investigations are aimed at establishing theoretical frame for CPT problem and numerical finite element analysis seems to be a prospective tool applicable to these purposes.

Most of the existing correlations between cone resistance and soil properties have been obtained by using one of the following five different approaches [2]: experimental methods, three basic theoretical approaches such as bearing capacity theory, cavity expansion theory and steady state deformation approach as well as conventional incremental finite-element analysis.

Until now, experimental methods are generally preferred for establishing correlations although the theoretical solutions have provided a useful framework of understanding.

When applying the bearing capacity theory, the cone resistance is assumed to be equal to the collapse load of a deep circular foundation in soil. Two analytical approaches, ie limit equilibrium and slip-line methods, were used for determining cone resistance $[3,4]$.

Cavity expansion theories have been suggested as being appropriate for the deep penetration problem [5-
7]. The limit solution for the cylindrical cavity pressure is widely assumed to be applicable to the estimation of the radial stress on the shaft, and the limit pressure for spherical cavity expansion is relevant to the end bearing pressure of the cone. However, it has been pointed out [8] that one of the inconsistencies with this approach is that it does not model correctly the strain paths followed by soil elements.

In isotropic homogenous soil, cone penetration may be treated as a steady state deformation of soil around a fixed cone penetrometer [9-11]. The pattern of deformation is described by steady state flow compatible with the boundary conditions. Certain class of undrained (incompressible) flow problems can be solved using particularly simple stream functions. The strain rates can be determined from the velocities at every point. The strain history of any material point as it moves along a streamline is then available. Given stress boundary conditions in the upstream direction it is now possible to integrate a constitutive (stress-strain) law along each streamline to give the stress throughout the soil. The resulting stresses derived from this approach may not satisfy all the equilibrium equations. This is because for $2 \mathrm{D}$ problems, such as cone penetration in undrained clays, the soil deformation is not completely decoupled from the soil strength parameters, although the coupling is believed to be quite weak for undrained problems. Because of the above 
source of uncertainty, the iterative procedure for adjusting the initial deformation to eliminate the equilibrium imbalance is suggested [9]. However, this iterative procedure cannot remove all the errors that exist in the strain path stress solutions [12].

In the last few decades, a fast development of numerical methods and computer technology enabled numerical modelling of various engineering problems. Conventional finite elements models have been extended to plasticity of soils [13-17], geometrical non-linearity [18 $20]$, porous media [21-24] as well as flow models [25, 26]. At the same time a large amount of geotechnical and civil engineering applications have been analysed by the FEM [27-30].

In general, the non-linear finite element method (FEM) [31] allows rigorous CPT solutions without simplifying assumptions for cone geometry or material behavior. However, the computational procedures has not been developed to such an extent that they could provide the numerical solution to be directly used in geotechnical practice.

In small strain FEM penetration analysis, the cone is introduced into a prebored hole, with the surrounding soil still in its in-situ stress state. An incremental plastic calculation is carried out and the collapse load is assumed to be equal to the cone resistance [32]. Such analysis is not capable of proper simulating the cone penetration, since during the cone movement, high lateral stresses tend to develop next to the cone shaft. As expected, a buildup of the above stresses will lead to a higher cone resistance than that predicted by a small strain analysis.

In order to include the effects of cone penetration on initial stress conditions, a large penetration analysis using large strains is required, since the cone must be pushed into soil with a vertical displacement of several times the diameter of the cone penetrometer. Cividini and Gioda (1988) [18] have presented some results of penetration into a Drucker-Prager frictional material. They have used zero-thickness elements to model the frictional interface behaviour between the cone and the soil. In their analyses the smoothness of the cone-soil interface is varied. Kousis et al (1988) [19] have also presented a large strain formulation and its application to the analysis of the cone penetration test in clay soil. Large cone penetration analysis is also presented by Sheng et al (1997) [33]. However, a large distortion of the finite element geometry during penetration leading to ill-conditioned equations and failure of iterative process restricted application of the FEM for modeling of CPT.

To avoid a large mesh distortion that occurs in the large cone penetration analysis, van den Berg (1994, 1996) $[25,26]$ uses an arbitrary Lagrangian-Eulerian formulation to uncoupled nodal point displacements and velocities from material displacements and velocities. Uncoupling of material and nodal point displacements implies that convection has to be taken into account to be able to update the state at the nodal points. As pointed out by Yu et al (2000) [34], the use of smoothing procedures for interpolating stress and strain fields does not always give stable and accurate solutions.

Recently to avoid the large mesh distortion a new computational tool remeshing technique [35-39] started to be applied in the conventional finite element analysis mainly for simulation of metal forming process. A few examples of application of remeshing to geotechnical problems have been also found in references [40-42], but direct applications to simulation of CPT have been not found. In the present study, the FE remeshing technique for simulating the large penetration of cone is developed and analysis of the cone penetration in undrained soil is provided.

\section{Problem definition}

In the CPT, a cone on the end of a series of rods is pushed into the ground at a constant rate and measurements of the resistance to penetration of the cone are made (Fig 1). The cone with a diameter $d$ of $35,7 \mathrm{~mm}$, cone tip angle $-60^{\circ}$ and penetration speed equals $2 \mathrm{~cm} / \mathrm{s}$ is widely used as a standard [43].

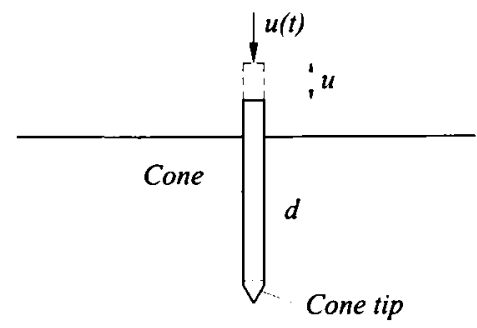

Soil

Fig 1. Cone penetration

Frequently, engineers working in geotechnical practice get measured CPT data as the cone resistance $q_{c}$ (the acting force on cone tip divided by the cone cross area), the skin friction and the pore water pressure, while mechanical properties of soil such as Youngs' modulus $E$, undrained shear strength $c_{u}$, friction angle $\phi$, etc are required to be used for deformation and stability analysis.

Generally, cone resistance problem reflects relationship

$$
q_{c}=q_{c}\left(E, c_{u}, \phi, \ldots\right) .
$$

Usually, for the undrail) is interpreted in terms of shear strength $c_{u}$ :

$$
q_{c}=N_{c} c_{u}+\sigma_{i},
$$

where $\sigma_{i}$ is average in-situ stress or vertical stress at penetration depth due to soil load.

A number of authors offer different expressions to determine cone factor $N_{c}$. Current investigations are 
aimed at developing theoretical frame and computation tool for determining $N_{c}$ by numerical experiments using FEM.

\section{Mathematical model}

Mathematical model explored here to describe large penetration problem is a standard continuum mechanics approach based on the equilibrium of internal and external virtual works in the actual configuration corresponding to time $t+\Delta t$. It is written for actual volume ${ }^{t+\Delta t} V$ as:

$$
\int_{t+\Delta t}{ }^{t+\Delta t} \tau_{i j} \cdot \delta^{t+\Delta t} e_{i j}{ }^{t+\Delta t} d V=\delta^{t+\Delta t} R,
$$

where the ${ }^{t+\Delta t} \tau_{i j}$ are the Cartesian components of the Cauchy stress tensor, the ${ }^{t+\Delta t} e_{i j}$ are the Cartesian components of an infinitesimal strain tensor and the $\delta^{t+\Delta t} R$ is the external virtual work.

Since the body undergoes large displacements and large strains providing unknown current configuration, and the constitutive relations are non-linear, the relation in (3) cannot be solved directly. However, an approximate solution can be obtained by referring all variables to a previously calculated known reference configuration at time $t$, and linearising the resulting equation.

To solve (3) the updated Lagrangian formulation is used. In this solution scheme all static and kinematic variables are referred to the reference configuration:

$$
\int_{t_{V}}^{t+\Delta t}{ }_{t} S_{i j} \cdot \delta^{t+\Delta t}{ }_{t} \varepsilon_{i j}{ }^{t} d V=\delta^{t+\Delta t} R
$$

in which ${ }^{t+\Delta t} S_{i j}$ is the 2nd Piola-Kirchhoff stress at time $t,{ }^{t+\Delta t}{ }_{t} \varepsilon_{i j}$ is Lagrangian strain at time $t+\Delta t$.

The linearisation of equation of motion (4) then resulted in the following relation:

$$
\begin{array}{r}
\int_{t_{V}}{ }^{t} C_{i j r s}^{e p} \cdot{ }^{t} e_{r s} \cdot \delta^{t} e_{i j}{ }^{t} d V+\int_{{ }^{t} V}{ }^{t} \tau_{i j} \cdot \delta^{t} \eta_{i j}{ }^{t} d V= \\
\delta^{t+\Delta t} R-\int_{{ }^{t} V}{ }^{t} \tau_{i j} \cdot \delta^{t} e_{i j}{ }^{t} d V,
\end{array}
$$

where ${ }^{\prime} C_{i j r s}^{e p}$ is the tangential material property tensor referred to the configuration at time $t ;{ }^{\prime} \tau_{i j}$ - the known Cauchy stress at time $t ;{ }^{t} e_{i j},{ }^{t} \eta_{i j}$ - the linear and nonlinear components of incremental strains ${ }^{t} \varepsilon_{i j}={ }^{t} e_{i j}+{ }^{t} \eta_{i j}$ which are referred to the configurations at time $t$.

Material property tensor ${ }^{t} C_{i j r s}^{e p}$ is derived using incremental theory of plasticity. Infinite small increment of the total strain increment $d^{t} \varepsilon_{i j}$ is assumed to be the sum of the elastic strain increment $d^{t} \varepsilon_{i j}^{e}$ and the plastic strain increment $d^{t} \varepsilon_{i j}^{p}$, ie:

$$
d^{t} \varepsilon_{i j}=d^{t} \varepsilon_{i j}^{e}+d^{t} \varepsilon_{i j}^{p}
$$

The elastic response is given by linear elastic constitutive relation

$$
d^{t} \sigma_{i j}=\mathrm{C}_{i j k l}^{e} d^{t} \varepsilon_{k l}^{e}
$$

where $C_{i j k l}^{e}$ is a constant fourth-order elasticity tensor.

The plasticity properties of soil is described by yield criterion

$$
f\left(\sigma_{i j}\right)=\sigma_{y}\left(\alpha_{i j}\right),
$$

where $\sigma_{y}$ is a yielding constant varying with hardening variable $\alpha_{i j}$.

The direction of the plastic strain increment is defined by flow rule. In case of undrained soil an associated flow rule may be used:

$$
d^{t} \varepsilon_{i j}^{p}=d \lambda \frac{\partial f}{\partial^{t} \sigma_{i j}},
$$

where $d \lambda$ is a positive scalar of proportionality dependent on the state of stress and load history.

Using Eqs (6)-(8) elastoplastic material property tensor is derived:

$$
{ }^{t} C_{i j k l}^{e p}=C_{i j k l}^{e}-\frac{\frac{\partial f}{\partial^{t} \sigma_{r \mathrm{~s}}} C_{i j r s}^{e} C_{m n k l}^{e} \frac{\partial f}{\partial^{t} \sigma_{m n}}}{H^{\prime}+\frac{\partial f}{\partial^{t} \sigma_{a b}} C_{a b c d}^{e} \frac{\partial f}{\partial^{t} \sigma_{c d}}},
$$

where $H^{\prime}$ is the hardening modulus, which for a perfect plasticity material becomes zero.

\section{Finite element discretisation}

For discretisation of problem (5) with respect to (10) the finite element method is used. A general displacement finite element formulation may be expressed by equilibrium equation

$$
[K(\mathbf{U}(t))] \Delta \mathbf{U}(t)=\Delta \mathbf{F}(t)
$$

where $[K(\mathbf{U}(t))]$ is the stiffness matrix of finite element assembling, which relates the vector $\Delta \mathbf{U}$ of the nodal displacement increments to the vector $\Delta \mathbf{F}$ of the total load increments.

The most usual finite element equation for updated Lagrange description is expressed as

$$
\left({ }^{t} K_{L}\right]+\left[{ }^{t} K_{G}\right) \Delta \mathbf{U}=\Delta \mathbf{F},
$$

where $\left[{ }^{t} K_{L}\right]$ and $\left[{ }^{t} K_{G}\right]$ are global linear and geometric (initial stress) stiffness matrices while the vector $\Delta \mathbf{F}$ presents the load vector with the effects of the element surface traction force, the element body force and the element initial stresses. 
By utilising shape functions for displacements in the incremental virtual work equation (5) stiffness matrixes are derived for each element $e$. Further, each incremental finite-element equation is assembled to construct the stiffness matrixes $\left[{ }^{t} K_{L}\right]$ and $\left[{ }^{t} K_{G}\right]$ for the whole region.

The linear stiffness matrix of element $\left[{ }^{t} K_{L}^{e}\right]$ is obtained from the first term of (5). The notion linear is used to reflect geometrical linearity, but, actually, this matrix involves material non-linearity. Finally, it is expressed as:

$$
\left[{ }^{t} K_{L}^{e}\right]=\int_{{ }^{\prime} V}\left[{ }^{t} B_{L}^{e}\right]^{T}\left[{ }^{t} C^{e p}\right]\left[{ }^{t} B_{L}^{e}\right] d V,
$$

where $\left[{ }^{t} C^{e p}\right]$ is elastoplastic material property matrix reflecting term (10) and $\left[{ }^{t} B_{L}^{e}\right]$ is linear strain-displacement transformation matrices. Geometrical stiffness (initial stress) matrix $\left[{ }^{t} K_{G}^{e}\right]$ is obtained from the second term of (5) as:

$$
\left.\left[{ }^{t} K_{G}^{e}\right]=\int_{t_{V}}^{\left[{ }^{t} B_{G}^{e}\right.}\right]^{T}\left[{ }^{t} \tau\right]\left[{ }^{t} B_{G}^{e}\right] d V,
$$

where $\left[{ }^{t} B_{G}^{e}\right]$ is non-linear strain-displacement transformation matrix, $\left[{ }^{t} \tau\right]$ is matrix of Cauchy stresses.

To describe the contact between the deformable soil and the rigid cone surface a special zero thickness contact elements are used. At each integration point these elements construct a measure of overclosure and measure of relative shear sliding. These kinematic measures are then used to introduce surfaces interaction theory. If $A$ is a point on the deformable surface, with current coordinates $x_{A}$ (Fig 2), the closest distance $h$ from $A$ to the rigid surface is determined according to

$$
n h=x_{A}-x_{c}-r,
$$

where $\boldsymbol{n}$ is the unit normal of the rigid surface at point $A^{\prime}$ which is the closest point to $A, x_{C}$ the coordinates of the reference node $C$ of the rigid body, and $r$ the vector from $C$ to $A^{\prime}$. If $h>0$, there is no contact between the surfaces at $\mathrm{A}$. If $h=0$, the surfaces are in contact. In

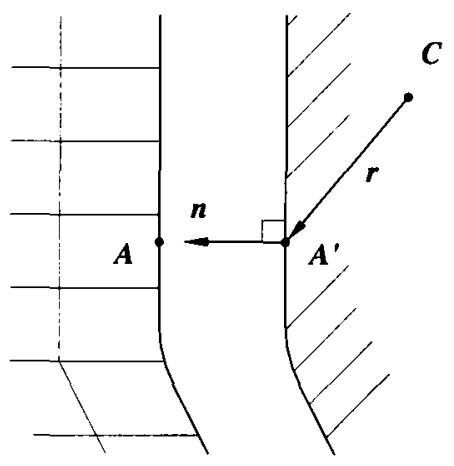

Fig 2. Soil-cone contact simulation numerical calculations small violations of this exact contact conditions are allowed.

The behaviour of the contact is defined by the Coulomb friction model, in which two contact surfaces can carry shear stresses up to a certain magnitude across their interface before they start sliding relative to one another; this state is known as sticking. The Coulomb friction model defines this critical shear stress, $\tau_{c r i t}$, at which sliding of the surfaces starts as a function of the contact pressure, $p$, between the surfaces:

$$
\tau_{\text {crit }}=\mu p,
$$

where $\mu$ is the coefficient of friction. Additionally, shear stress limit, $\tau_{\max }$, is used, so that, regardless of the magnitude of the contact pressure stress, sliding will occur if the magnitude of the equivalent shear stress reaches this value. Finally, the sliding surface is described by line segment in plane $\tau-p$, which for Coulomb frictional model is presented on Fig 3.

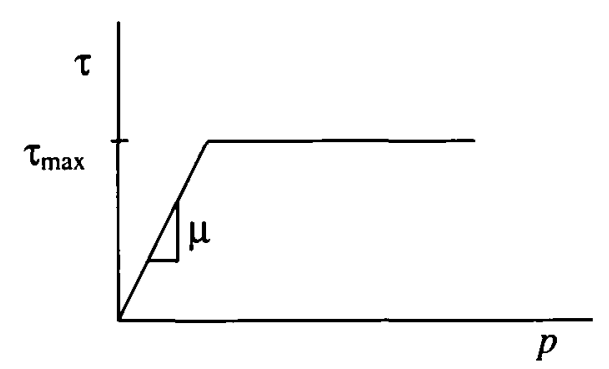

Fig 3. Coulomb friction model

Then the equation (11) is solved by increments using Newton-Rapson iterative technique.

\section{Large penetration without remeshing}

Usually updated Lagrangian formulation (5) and its FE model (12) are related to fixed finite element mesh. The first stage in numerical analysis of CPT is to verify suitability or drawbacks of the traditional approach to large penetration problem.

The penetration of the standard geometry cone penetrating the soil is considered in this verification example. The rigid cone is introduced into a prebored hole. The initial state of soil defined by the weight $\gamma=18 \mathrm{kN} / \mathrm{m}^{3}$ and lateral pressure ratio $K_{0}=1,0$. The soil is assumed to be elastic-perfectly plastic incompressible Mises material with Young's modulus $E=30 \mathrm{MPa}$, Poisson's ratio $v=0,495$ and the yield stress $\sigma_{y}=40 \mathrm{kPa}$.

Since cone is penetrating by vertical loading, the 3D solid problem may be reduced to axisymmetric problem with $2 \mathrm{D}$ discretisation domain (Fig 4) having dimensions $h+H=1,25 \mathrm{~m}, D=0,625 \mathrm{~m}$. The soil is modelled using the four-noded axisymmetric elements with four Gauss points. The penetration process itself is initiated by applying displacement $u$ to the rigid cone.

The numerically obtained loading curve relating resultant load $F$ acting on the tip of cone (Fig 4) and cone 
displacement $u$ as well as distortion of initial finite element mesh are the most important characteristics and, at the same time, quality indicators of numerical analysis. As it follows from a simple observation, the large distortion of mesh (Fig 5b) and cyclic variations of loading curve (Fig 5c) are far from being satisfactory for qualitative assessment of numerical solution.

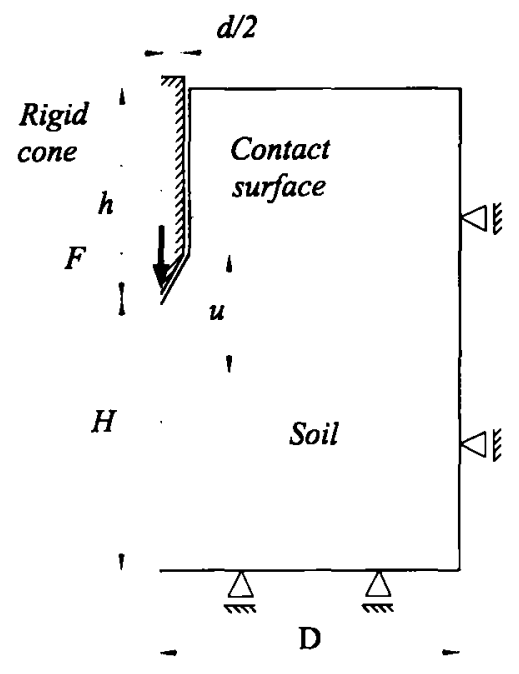

Fig 4. Numerical model

a)

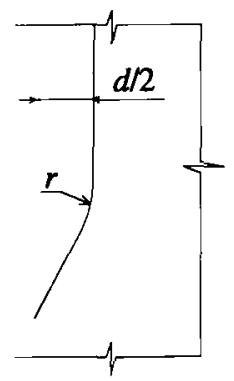

c)

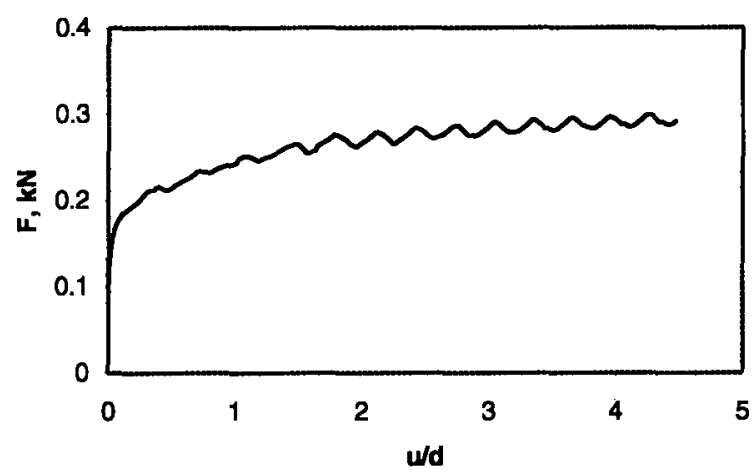

Fig 5. Results of analysis without remeshing using a smooth cone with $r=30 \mathrm{~mm}$ : a) idealised geometry of the cone, b) deformed mesh, c) loading curve
By sliding of the cone with respect to solid the outer contact solid node after certain time sliding looses the contact with conical surface of the cone and moves along the vertical surface. The cyclic character of loading curve may be explained as a consequence of jumping of individual nodes during sliding. Finally, cycling step is related to the dimension of the contact finite element.

The traditional procedure of finite element refinement leads even to large distortion of mesh and penetration process fails down at smaller displacement values. To avoid such a large mesh distortion larger elements can be used $[33,44]$, but in this case accuracy of calculated stress values decrease dramatically. By using small rounded radius, finally tending to sharp angle, and by increasing the roughness of contact this tendency is even worse. The results of simulation of rough cone presented in Fig 6 show much more heavy distortion of mesh and irregular character of loading curve, which clearly indicates unsatisfactory validity of numerical simulation. To overcome this difficulty, a remeshing technique will be given below.

\section{Remeshing technique}

Remeshing as regeneration of the mesh together with the transfer of the state variables to new mesh, comprises a loop of operations until required overall penetration has been reached:

1) Solution of non-linear analysis problem with initial mesh.

a)

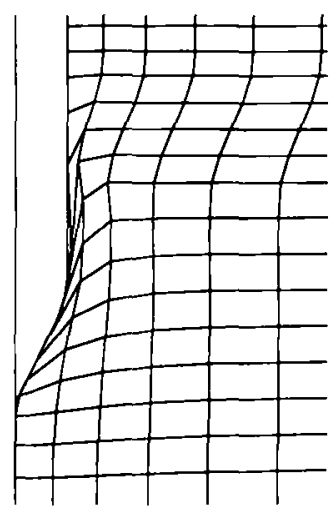

b)

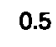

0.4

$z^{0.3}$

$\mathrm{L}^{\circ} 0.2$

0.1

0

0

0.5

1
$w / d$

1.5

2

Fig 6. Results of analysis without remeshing using a rough cone: a) deformed mesh, b) loading curve 
2) Regeneration of the new mesh using the deformed domain boundary.

3) Transfer of state variables from the deformed initial mesh into the new mesh.

The remeshing techniques can be constructed by applying extra/interpolation transfer of state variables method, where extrapolation of the state variables to initial mesh nodes, averaging and then interpolation to a new mesh is performed. Due to numerical difficulties by calculating of stresses in displacement finite element models, accuracy of this technique can be, however, not sufficient to model the high-gradient stress field around the cone (Fig 7).

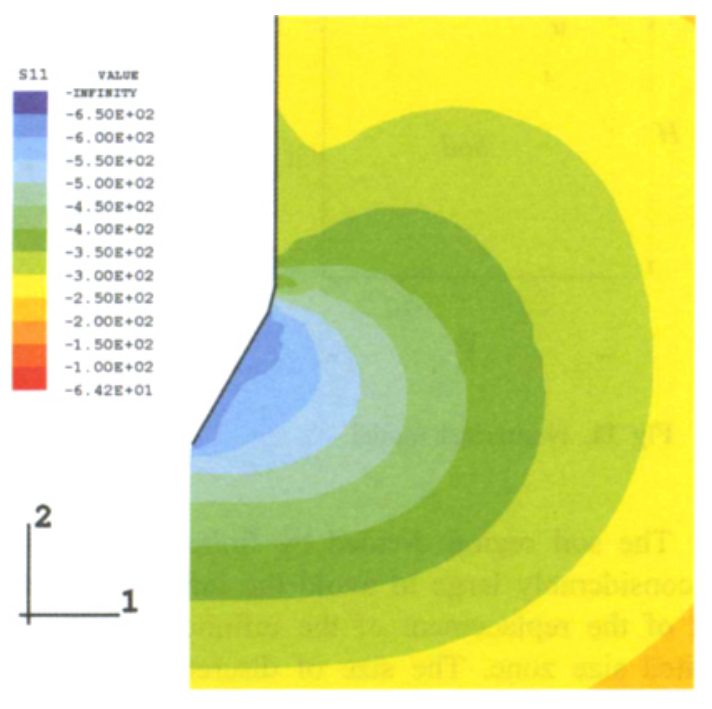

Fig 7. Stress field around cone tip

To improve numerical accuracy the moving least square method using superconvergent patch recovery (SPR) technique [45] has been applied for transfer of state variables. It is developed by the authors and implemented into software compatible with ABAQUS [46] finite-element code.

The transfer operation using moving least-squares method consists of the following steps: constructing the patches from the Gauss points of the old elements mesh, finding in which patch the Gauss point of the new element is, transfer of the variables from the Gauss points of the old mesh to the Gauss points of the new mesh using the polynomial function and the least-squares method. These steps are illustrated in Fig 8.

The validity of remeshing technique has been tested for simulating CPT problem where frictionless sliding contact surface with a small rounded radius $r=2 \mathrm{~mm}$ was assumed. The material parameters were defined in previously examples. A typical loading curve of CPT (Fig 9) obtained by remeshing technique contains jumpings, frequency of which is related to frequency of remeshing steps. Interpretation of results shows that jumping has mainly three reasons. The first reason is related to shifting of the nodal points by mesh regeneration, the second one is related to corner node sliding, while the third one is related to transfer procedure. As it follows from the figure, using different approximation approaches, different loading curves 1,2 or 3 may be obtained.

To investigate convergence, the calculations based on different frequency between remeshing and various mesh densities have been performed. Loading curves presented in Fig 10 obtained using various meshes with $458,1632,3541$ and 6472 elements, where $4,8,12$ and 16 elements on cone tip were used respectively. Cone displacements between remeshing steps was taken about a half size of the element on the cone. However, refinement of the mesh and remeshing interval are time-con-

a)

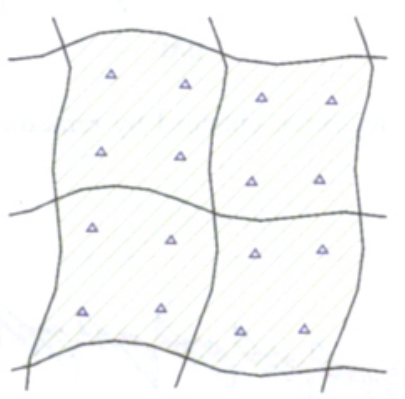

b)

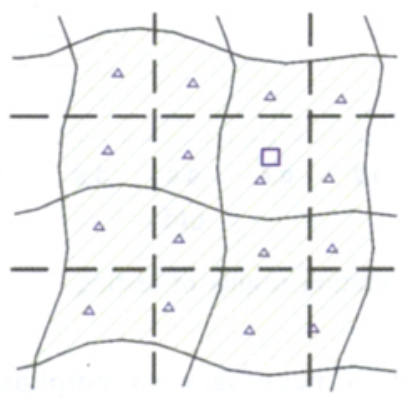

c)
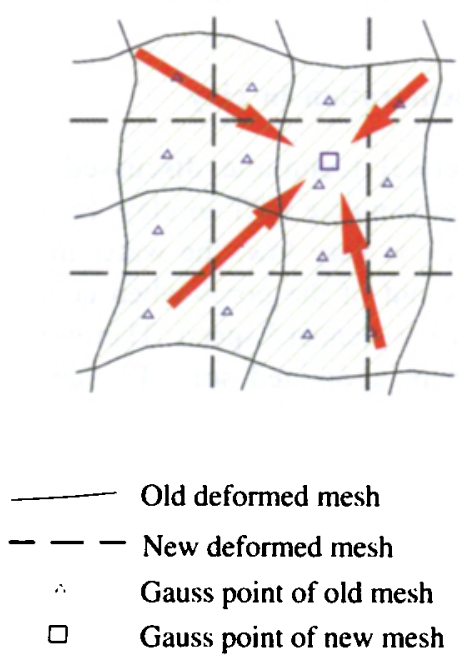

Fig 8. Illustration of the moving least-squares method: a) constructing the patch in the deformed initial mesh, b) finding in which patch the new Gauss point is, c) interpolation of the variables 
suming processes. On the other hand, a thorough examination of the results gives an opportunity to construct a smooth curve directly, which is actually equilibrium curve 2 (Fig 9) obtained by coarse mesh and relative large remeshing interval.

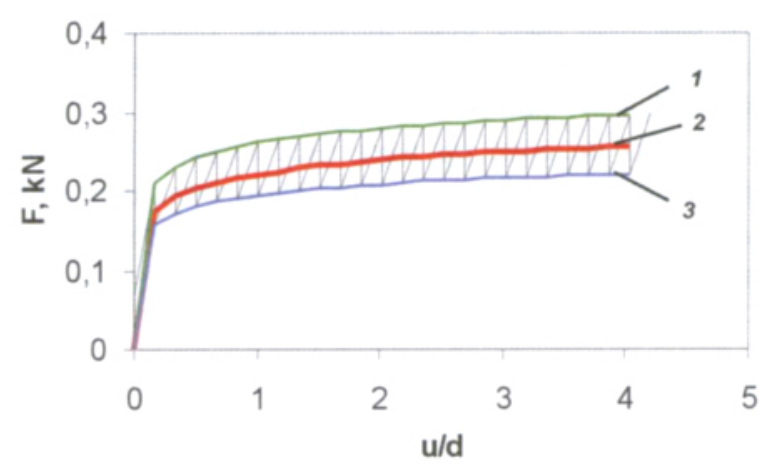

Fig 9. Loading curve obtained by remeshing technique

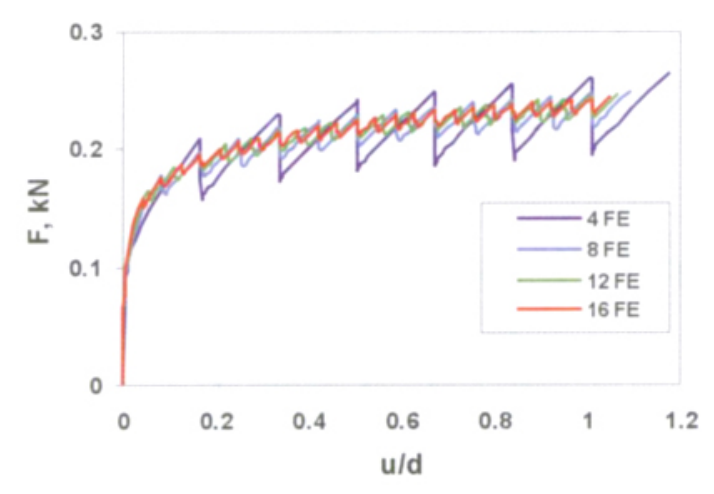

Fig 10. Illustration results of testing

Finally, it is necessary to emphasise that the remeshing technique developed also comprised evaluation of smooth loading curve for CPT.

\section{The cone penetration in clay}

The numerical technique discussed and verified above is used to simulate CPT in clay. Since water permeability of clay is very low, the water in this soil has no time to flow out of the pores when cone penetration is performed at the standard speed. Therefore, cone penetrates completely undrained soil [47], and elastic-perfectly plastic incompressible Mises material may be applied for clay [48].

An elastic-plastic soil model with Mises yield criteria and the following clay parameters were used: Young's modulus $E=22,5 \mathrm{MPa}$, Poisson's ratio $v=0,495$, weight $\gamma=18 \mathrm{kN} / \mathrm{m}^{3}$, lateral pressure ratio $K_{0}=1,0$. As it obvious in undrained soil analysis, yield stress $\sigma_{y}$ is simple related to undrained shear strength as $\sigma_{y}=2 c_{u}$. Shear strength cu can be obtained from triaxial compression test [49] and is taken as $c_{u}=50 \mathrm{kPa}$. These parameters define rigidity index $I_{r}=150$.

To avoid boundary effects at the start of the analysis, the cone is placed into prebored hole $h=0,55 \mathrm{~m}$ (Fig 11), with the surrounding soil still in its in-situ stress state.

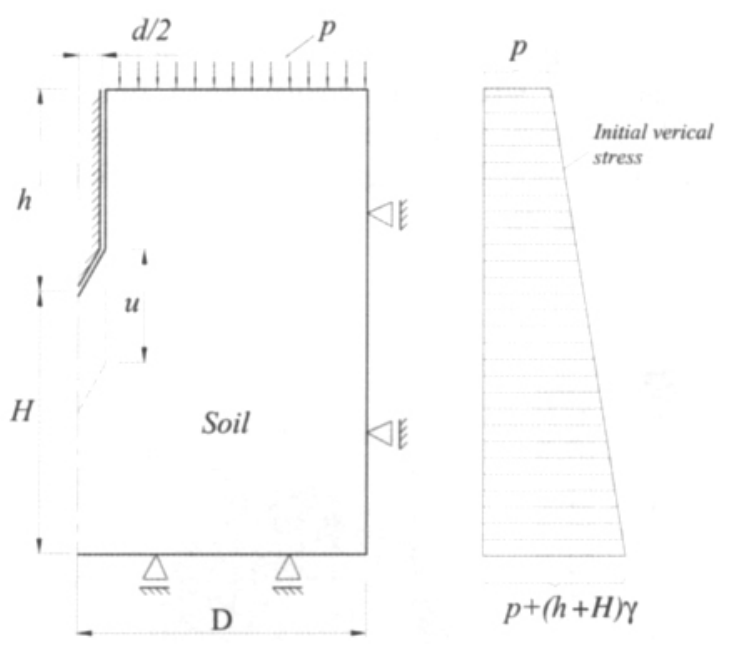

Fig 11. Numerical model

The soil region divided by finite elements should be considerably large to avoid the influence on the result of the replacement of the infinite half-space by a limited size zone. The size of discretised domain was taken according to $\mathrm{Yu}$ et al [12] with $D=1,1 \mathrm{~m}, h+H=$ $1,8 \mathrm{~m}$ and verified with more large discretised domain. The upper soil layer $h_{s}=4,45 \mathrm{~m}$ has been removed and his influence was replaced by adding additional external pressure $p=80 \mathrm{kPa}$ to the free soil surface (Fig 11). The penetration process is initiated by applying displacement $\mathrm{u}$ to the cone, until a steady state is reached. The reaction force $F$ on the cone tip at the steady state divided by the cone area is assumed to be cone resistance qc. The domain was discretised into 1944 bilinear four nodded elements, while soil-cone interaction is described by contact surface [46]. The total value of DOF of the model equals to 5082 .

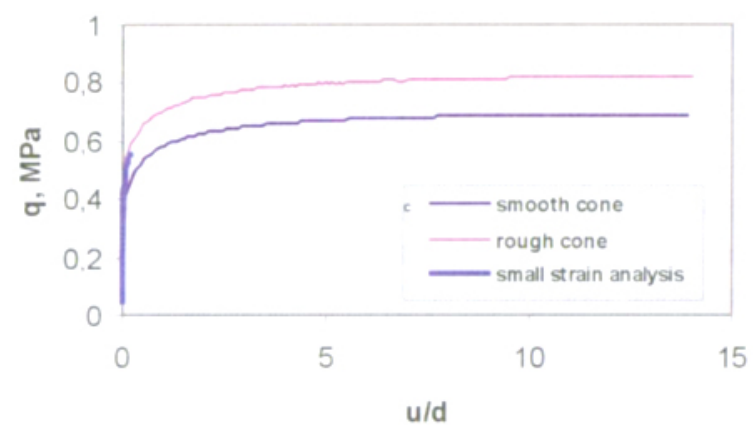

Fig 12. Results of cone penetration in clay 
The remeshing technique developed is able to overcome difficulties caused by the sharp corner and roughness of the cone. The load-displacement curves obtained using fully smooth penetrometer (ie no friction between penetrometer and clay) and fully rough penetrometer (ie friction between penetrometer and clay is equal to clay shear strength) are shown in Fig 12. For illustrating the capability of large displacement approach, the loading curve obtained by small strain analysis is also given in the figure. The above curves may be considered as envelope for different cone-clay friction values.

The results of calculations are expressed in terms of the cone factor $N_{c}$ presented in Table and compared to the other solutions.

Values of theoretical and experimental cone factors derived by using different methods

\begin{tabular}{|l|c|c|}
\hline \multirow{2}{*}{ Description } & \multicolumn{2}{|c|}{$N_{c}$} \\
\cline { 2 - 3 } & smooth & rough \\
\hline $\begin{array}{l}\text { Curent authors results, FEM, large } \\
\text { strain with remeshing }\end{array}$ & 11,8 & 14,4 \\
\hline $\begin{array}{l}\text { Results obtained by the author via small } \\
\text { strain FEM, rough cone tip [50] }\end{array}$ & \multicolumn{2}{|c|}{$8,5-9,4$} \\
\hline $\begin{array}{l}\text { Mayerhof (1951), bearing capacity } \\
\text { theory, rough base [1] }\end{array}$ & \multicolumn{2}{|c|}{9,7} \\
\hline $\begin{array}{l}\text { Vesic (1972), spherical cavity } \\
\text { expansion theory [5] }\end{array}$ & \multicolumn{2}{|c|}{8,0} \\
\hline Yu (1993), cavity expansion theory [7] & 9,8 & 15,0 \\
\hline $\begin{array}{l}\text { Van den Berg and Vermeer (1994), } \\
\text { large strain FEM analysis by Arbitrary } \\
\text { Lagrangean-Eulerian approach [25] }\end{array}$ & 13,6 & 17,5 \\
\hline $\begin{array}{l}\text { Yu et al (2000), steady state FEM [34] } \\
\text { Yunne and Kleven (1981), } \\
\text { experimental, normally consolidated } \\
\text { clays [51] }\end{array}$ & \multicolumn{2}{|c|}{$11-19$} \\
\hline $\begin{array}{l}\text { Kurup et al (1994), experimental, } \\
\text { calibration chamber testing, average } \\
\text { results on specimen with rigidity index } \\
\text { 150 [52] }\end{array}$ & \multicolumn{2}{|c|}{15,72} \\
\hline
\end{tabular}

The obtained cone factor for given soil parameters is $N_{c}=11,8$ for smooth cone and $N_{c}=14,4$ for rough cone. As it was expected, solution of bearing capacity theory is smaller as authors results obtained by FEM with remeshing. This is because the bearing capacity theory neglects the influence of the initial stress states around the shaft. In particular, the horizontal stress tends to increase around the cone shaft after cone penetration, and the influence of this change on the cone resistance is not considered in bearing capacity analysis.

For the same reason as bearing capacity theory, the small strain FE analysis [50] gives to small cone factor $N_{c}=8,5-9,4$.

In cavity expansion theory, both elastic and plastic deformations of the soil during cone penetration and the influence of the cone penetration process on initial stress states can be taken into account. The cone factor from spherical cavity expansion solution Vesic (1972) [5] is $N_{c}=8,0$. More advanced solutions give higher values $[6,7]$.

Lunne and Kleven (1981) [51] showed that for normally consolidated marine clays with field vane as the reference test, the cone factor $N_{c}$ varied between 11 and 19 with an average value of 15 .

Kurup et al (1994) [52] have presented the results of a calibration chamber study on CPT in cohesive soils. His test was performed on overconsolidated sample with overconsolidation ratio of 5 and rigidity index $I_{r}=150$ and provides average value of the cone factor $N_{c}=15$. The current investigation is performed on the clay which have the same rigidity index $I_{r}=150$, but Mises model strictly speaking corresponds to lightly overconsolidated clays with overconsolidation ratio of 2 [12] which should give lower values of the cone factor. Therefore the obtained values for rough cone $N_{c}=14,4$ is in a very good agreement with experimental results.

\section{Conclusions}

On the basis of numerical investigation the following conclusion has been drawn:

1. Large distortion of the finite elements is a serious obstacle in the application of the conventional displacement finite element method to large displacement analysis, and remeshing technique developed is one of the prospective computational techniques to be used for modelling purpose.

2. Remeshing technique, which uses moving least square method based on SPR technique for transfer of state variables, is developed and implemented into software compatible with standard FEM code. Validity of the remeshing is illustrated in modelling of CPT tests.

3. Remeshing technique is supplied by approximation procedure, which allows constructing smooth CPT loading curve on relative coarse finite element discretisation and remeshing frequency.

4. The developed remeshing technique is applied to smooth and rough cone test in clay, where large penetration of cone $u=14 d$ is reached. The obtained cone factors are 11,8 and 14,4 for smooth and rough cone respectively. The solutions obtained are compatible with other theoretical solutions and provides good agreement with experimental results.

5. The remeshing technique is universal and may be used in other problems, but future research and verification of technical remeshing details is required for particular cases.

\section{Acknowledgement}

Financial support of the German Academic Exchange Service for this investigation partially performed in TU Darmstadt is gratefully acknowledged. 


\section{References}

1. Lunne, T.; Robertson, P. K. and Powell, J. M. Cone penetration testing in geotechnical practice. London: Blackie Academic \& Professional, 1997. 312 p.

2. Yu, H. S.; Mitchell, J. K. Analysis of cone resistance: review of methods. Journal of Geotechnical and Geoenvironmental Engineering, ASCE, Vol 124, No 2, 1998, p. 140149.

3. Terzaghi, K.; Peck, R. B. Soil mechanics in engineering practice. New York: John Wiley \& Sons, 1948. $566 \mathrm{p}$

4. Sokolovskii, V. V. Statics of granular media. Tarrytown, N.Y: Pergamon Press, 1965.

5. Vesic, A. Expansion of cavities in infinite soil mass. $J$. Soil Mechanics and Foundations Division, ASCE, 98(3), 1972, p. 265-290.

6. Baligh, M. M. Theory of deep static cone penetration resistance. Rep. No R75-56, Dept of Civ and Envir Engrg, Massachusett Institute of Technology, Cambridge, Mass, 1975.

7. Yu, H. S. Discussion on singular plastic fields in steady penetration of a rigid cone. J. Appl. Mech., 60, 1993, p. 1061-1062.

8. Baligh, M. M. Undrained deep penetration, I: Shear stresses. Géotechnique, 36(4), 1986, p. 471-485.

9. Baligh, M. M. Strain path method. J. of Geotechnical Engineering, ASCE, 111(9), 1985, p. 1108-1136.

10. Teh, C. I.; Houlsby, G. T. Analysis of the cone penetration test by the strain path method. In: Proc. of VI Inter. Conf. on Numerical Methods in Geomechanics, Innsbruck. Rotterdam: Balkema, 1988, p. 397-402.

11. Houlsby, G. T.; Teh, C. I. Analysis of the piezocone in clay. In: Proc. of the First International Symposium on Penatration Testing /ISOPT-1/, Orlando. Rotterdam: Balkema, 1988, Vol 2, p. 777-783.

12. Yu, H. S.; Herrmann, L. R.; Boulanger, R. W. Analysis of steady cone penetration in clay. Journal of Geotechnical and Geoenvironmental Engineering, ASCE, Vol 126, No 7, 2000, p. 594-605.

13. DiMaggio, F. L.; Sandler, I. S. Material models for granular soils. J. Eng. Mech. Div., ASCE, 97 (EM3), 1971, p. 935-950.

14. Lade, P. V. Elasto-plastic stress strain theory for cohesionless soil with curved yield surface. Int. J. Solids Struct., 13, 1977, p. 1014-1035.

15. Schofield, A. N.; Wroth, C. P. Critical State Soil Mechanics. New York: McGraw-Hill, 1968. 310 p.

16. Lui, M. D.; Carter, J. P. A structured cam clay model. Can. Geotech. J., 39(6), 2002, p. 1313-1332.

17. Tamagnini, C.; D'Elia, M. A simple bounding surface model for bonded clays. In: Proc. of 2th Int. Symposium on Pre-failure Deformation Characteristics of Geomaterials. Rotterdam: A. A. Balkema, 1999, p. 565-572.

18. Cividini, A.; Gioda, G. A simplified analysis of pile penetration. In: Proc. 6th Int. Conf. Numerical Methods in Geomechanics. Rotterdam: A. A. Balkema, 1988, p. 10431049.

19. Kiousis, P. D.; Voyiadjis, G. Z. and Tumay M. T. A large strain theory and its aplication in the analysis of the cone penetration mechanism. Int. J. Numerical and Analytical Methods in Geomechanics, No 12, 1988, p. 45-60.

20. Hu, Y.; Randolph, M. F. A practical numerical approach for large deformation problems in soil. Int. J. Numer. Anal. Meth. Geomech., Vol 22, 1998, p. 327-350.

21. Biot, M. A. General theory of three-dimensional consolidation. J. Appl. Phys., 12, 1994, p. 155-164.

22. Goodman, M. A. and Cowin, S. C. A continuum theory for granular materials. Arch. Rational Mech. Anal., 44, 1972, p. 249-266.

23. Voyiadjis, G. Z. and Abu-Farsakh, M. Y. Coupled theory of mixtures for clayey soils. Computers and Geotechnics, Vol 20, 1997, p. 195-222.

24. Teh Cee Ing and Nie Xiaoyan. Coupled consolidation theory with non-Darcian flow. Computers and Geotechnics, Vol 29, 2002, p. 169-209.

25. Van den Berg P. Analysis of soil penetration. PhD Thesis. Delft University of Technology, The Netherlands, 1994. $173 \mathrm{p}$.

26. Van den Berg P.; de Borst, R.; Hučtink, H. An Eulerian finite element model for penetration in layered soil. Int. J. Numer. Anal. Meth. Geomech., 20(12), 1996, p. 865-886.

27. Katzenbach, R.; Arslan, U.; Moorman, Chr.; Reul, O. Piled raft foundation - Interaction between piles and raft. In: Proc. Int. Conf. on Soil-Structure Interaction in Urban Civil Eng., Darmstadt Geotechnics, 4(2), 1998, p. 279-296.

28. Katzenbach, R.; Schmitt, A. and Turek, J. Three-dimensional modelling and simulation of combined piled-raft foundations for high rise structures. In: Proc. of the Ninth International Conference on Computing in Civil and Building Engineering, Taipei, Taiwan, 2002, Vol 2, p. 903-908.

29. Bukotas, G.; Kačianauskas, R. Analysis of assimetric boretype foundation in respect of plastic deformation. Civil Engineering (Statyba), No 2(10), 1997, p. 24-31 (in Lithuanian).

30. Yoo, C. Finite-element analysis of tunnel face reinforced by longitudinal pipes. Computers and Geotechnics, 29, 2002, p. 73-94.

31. Bathe, K. Finite element procedures. Englewoods Cliffs: Prentice-Hill, 1995. 1037 p.

32. de Borst, R. and Vermeer, P. A. Finite element analysis of static penetration tests. In: Proc., 2nd Eur. Symp. on Penetration Testing, Vol 2, 1982, p. 457-462.

33. Sheng, D.; Axelsson, K.; Magnusson, O. Stress and strain fields around a penetrating cone. In: Proc. VI Intern. Symposium on Numerical Models in Geomechanics / NUMOG VI . Rotterdam: Balkema, 1997, p. 653-660.

34. Yu, H. S.; Herrmann, L. R.; Boulanger, R. W. Analysis of steady cone penetration in clay. Journal of Geotechnical and Geoenvironmental Engineering, ASCE, Vol 126, No 7, 2000, p. 594-605.

35. Hamel, V.; Roelandt, J. M.; Gacel, J. N.; Schmit, F. Finite element modeling of clinch forming with automatic remeshing. Computers and Structures, Vol 77, 2000, p. $185-200$.

36. Peric, D.; Jr M.; Owen, D. R. J. On adaptive strategies for large deformations of elasto-plastic solids at finite strains: computational issues and industrial applications. Comput. Methods Appl. Mech. Engrg., Vol 176, 1999, p. 279-312. 
37. de Araujo, T. D.; Roehl, D.; Martha, L. F. An adaptive strategy for elastic-plastic two-dimensional finite element analysis. In: Proc. of ECCOMAS 2000, volume on CDROM, Barcelona, 2000. $17 \mathrm{p}$.

38. Peric, D.; Dettmer, W.; Jr M. Issues on computational modelling of strongly nonlinear solid mechanics problems. In: Proc. of ECCOMAS 2000, volume on CD-ROM, Barcelona, 2000. 22 p.

39. Erhard, T.; Taenzer, L.; Diekmann, R.; Wall, W. A. Adaptive remeshing issues for fast transient, highly nonlinear processes. In: Proc. of ECCM-2001, volume on CD-ROM, Cracow, 2001. 25 p.

40. Hu, Y.; Randolph, M. F. A practical numerical approach for large deformation problems in soil. Int. J. Numer. Anal. Meth. Geomech., Vol 22, 1998, p. 327-350.

41. Hu, Y.; Randolph, M. F. and Watson, P. G. Bearing response of skirted foundation on nonhomogeneous soil. Journal of Geotechnical and Geoenvironmental Engineering, ASCE, Vol 125, No 11, 1999, p. 924-935.

42. Liyanapathirana, D. S.; Deeks, A. J.; Randolph, M. F. Numerical modelling of large deformations associated with driving of open-ended piles. Int. J. Numer. Anal. Meth. Geomech., 24(14), 2000, p. 1079-1101.

43. Rep. of ISSMFE T.C. 16 on ground property characterisation from in-situ testing. inernational reference test procedure for the cone penetration test (CPT) and the cone penetration test with pore presure (CPTU)with pore presure. In: Proceedings of the Twelfth ECSMGE Geotechnical Engineering for Transportation Infrastucture. Rotterdam: A. A. Balkema, Vol III, 1999, p. 2195-2222.
44. Mabsout, M.; Reese, L.; Tassoulas, J. Study of pile driving by finite-element method. $J$. Geotechnical Engineering, ASCE, Vol 121, No 7, 1995, p. 535-543.

45. Zienkiewicz, O. C.; Zhu, J. Z. The superconvergent patch recovery and a posteriori error estimates. Part 1: The recovery Technique. Int. J. Num. Meth. Eng., 33, 1992, p. 1331-1364.

46. ABAQUS / Standard. User's manuals. Version 5.8. Habbitt, Karlsson \& Sorensen, Inc. 1998.

47. Jamiolkowski, M.; Ladd, C. C.; Germaine, J. T.; Lancellotta, R. New developments in field and laboratory testing of soils. In: Proceedings of the Eleventh ICSMFE. San Francisco, Rotterdam: A.A.Balkema, Vol I, 1985, p. $57-153$.

48. Ukritchon, B.; Whittle, A. J.; Sloan, S. W. Undrained limit analyses for combined loading of strip footings on clay. Journal of Geotechnical and Geoenvironmental Engineering, ASCE, Vol 124, No 3, 1998, p. 265-276.

49. Mitchell, J. K. Fundamentals of soil behavior. New York: John Wiley \& Sons. 1993. 437 p.

50. Markauskas, D.; Kačianauskas, R.; Sukšta, M. Modelling the cone penetration test by the finite element method. In: Foundation of civil and environmental engineering. Poznan: Publishing house of Poznan University of Technology, 2002, p. $125-140$.

51. Lunne, T.; Kleven, A. Role of CPT in North Sea foundation engineering. In: Session at the ASCE National Convention: Cone Penetration Testing and Materials, St. Louis, ASCE, 1981, p. 76-107.

52. Kurup, P.; Voyiadjis, G.; Tumay, M. Calibration chamber studies of piezocone test in cohesive soils. J. of Geotechnical Engineering, ASCE, 120(1), 1994, p. 81-107. 